\title{
Developing a Decision Support System for Water Resources Dispatching
}

\author{
Yu FENG ${ }^{\mathrm{a}, \mathrm{b}, \mathrm{c}}$, Jijun XU ${ }^{\mathrm{b}, \mathrm{c}, 1}$, Weirong SHENG ${ }^{\mathrm{d}}$, Jitian $\mathrm{CHEN}^{\mathrm{d}}$, Yang $\mathrm{HONG}^{\mathrm{a}}$ \\ ${ }^{a}$ School of Earth and Space Sciences, Peking University, Beijing 100871, China \\ ${ }^{b}$ Changjiang River Scientific Research Institute of Changjiang Water Resources \\ Commission, Wuhan 430010, China \\ ${ }^{c}$ Research Center on the Yangtze River Economic Belt Protection and Development \\ Strategy, CWRC, Wuhan 430010, China \\ ${ }^{d}$ Hydrology bureau of Jiangxi Province, Nanchang 330025, China
}

\begin{abstract}
Contradiction between water demand and water supply have a huge impact on social and economic development. This paper presents the development of a water resources dispatch decision support system. The system integrates models related to water dispatch such as streamflow forecast model, water allocation model and water dispatch model. Each model runs as an independent service and is registered in the model platform. The model platform interacts with the service layer and data layer through the model adapter. The model adapter is designed for converting the model input data sent by the service layer and the basic data and observation data queried by the data layer into the format required by the model. In case study, we took the Fu River Basin as an example to demonstrate an application of the system. The system realizes the complete process of data collection, streamflow forecast, water demand declaration, water distribution and water dispatch. User can get the recommended operation plan of the reservoir and the corresponding water supply result through the user interface. Process variables can also be viewed through the system, such as streamflow forecast results and water distribution results, etc. The proposed system can provide technical support and assistance for the decision makers, which also provide an effective demonstration for water resources management in other rivers.
\end{abstract}

Key words. Decision support systems, streamflow forecast, water resource dispatch

\section{Introduction}

Water supply is an essential service that any community need to securely provide [1]. With the development of industrialization and urbanization, the shortage of water resources will become more and more severe due to the growing population and worsening river ecological health [2]. The conflict of water allocation among competing municipal, industrial and agricultural interests is more and more prominent [3-4]. In order to realize the efficient use of water resources and alleviate the imbalance between the supply and

\footnotetext{
${ }^{1}$ Corresponding Author: Jinjun Xu, Changjiang River Scientific Research Institute of Changjiang Water Resources Commission, Wuhan 430010, China; E-mail: xujj07@163.com

This work is supported by the National Natural Science Foundation of China (Grant No. 52009005) and the National Public Research Institutes for Basic R and D Operating Expenses Special Project (no. CKSF2019212/SZ). We also acknowledge the entire development team, without whose help this research could not have been achieved.
} 
demand of water resources, it is necessary to carry out water resources dispatching to meet different needs [5].

In recent years, although researches on water resource dispatching have been carried out, most advances in water resource dispatching models are concealed to the academic arena [6-7]. The usage of water resource dispatching model to actual scenarios remains to be explored [8]. Decision support system (DSS) is an effective way to apply these models to actual scenarios [9]. It helps dispatchers to solve water resource dispatch problems and make decisions through an interactive interface [10]. Researchers proposed the design of DDS based on their own research models [11-13], but most of them are more inclined to the model design. Other researches have improved DDS from the aspect of computer technology, such as [14-15].

In this paper, we focus on the integration of the water resource dispatching models and carried out the research on the development of water resources decision support system. Architecture of the DSS is described. And we also discussed how the model is integrated into the system through the model adapter. This DSS integrated regular scheduling and optimized scheduling models considering different dispatch objects such as flood control, irrigation, water supply, power generation and ecology. These DSS are applied to the water resource dispatching of Fu River in Jiangxi Province, China. In case study, we showed the user interface of the DSS. The system provides an effective means for dispatchers to solve water resource dispatch problems and make decisions.

\section{Materials and Methods}

\subsection{System Structure}

The water resource dispatch decision support system mainly serves the water resource management during the dry season. The system is designed based on a microservice architecture. Applications in the system are split into sub-services. Each service runs in a separate process, and the services use restful APIs to cooperate with each other. Models related to water resource dispatch are also run separately as services. Architecture of the system is shown in Figure 1.

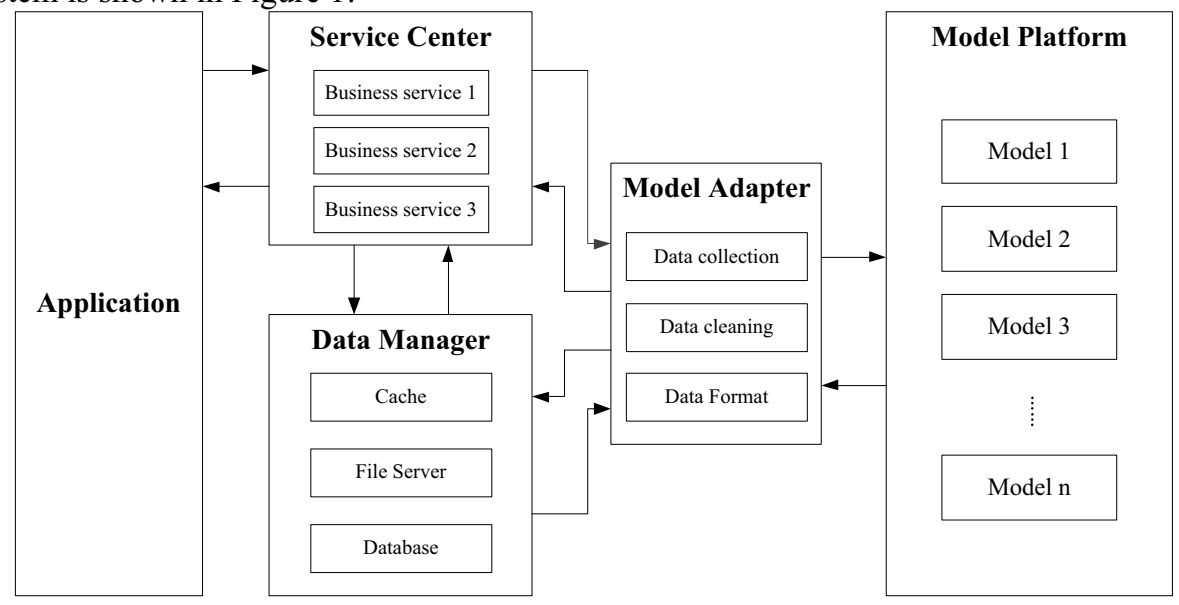

Figure 1. Design of the DSS. 
The system is divided into five parts, including Application, Service Center, Data Manager, Model Adapter and Model Platform. The Application provides users with a friendly User Interface, and offers a unified entrance for all users to access the system. The Service Center contains all the business services of the system, such as logical business services, log services, monitoring services, etc. Model calculation requests are also forwarded by the service center. Data Manager is an important component for the system to organize and manage data. Data in the database, Redis and file system is read through the data manager. Model Platform realizes the unified management of the model. Models related to water resource dispatch are registered and managed by the model platform. Model Adapter is the middleware between the model platform and the service layer. The responsibility of model adapter is to collect the necessary basic data and observation data for the model, and convert user input into the format required by the model. The data cleaning component is also implemented in the model adapter.

\subsection{Model Platform Design}

The Model Platform integrates the mathematical models involved in the water resources dispatch process, such as streamflow forecasting model, water allocation model and water dispatch model. The platform also provides model registration service if there are new models that need to be integrated. The platform will provide calling interface for the registered model.

All model integrated in the model platform is designed based on the black box theory. As shown in Figure 2, coupling between models is prohibited. The interaction among different models can only be done through input and output.

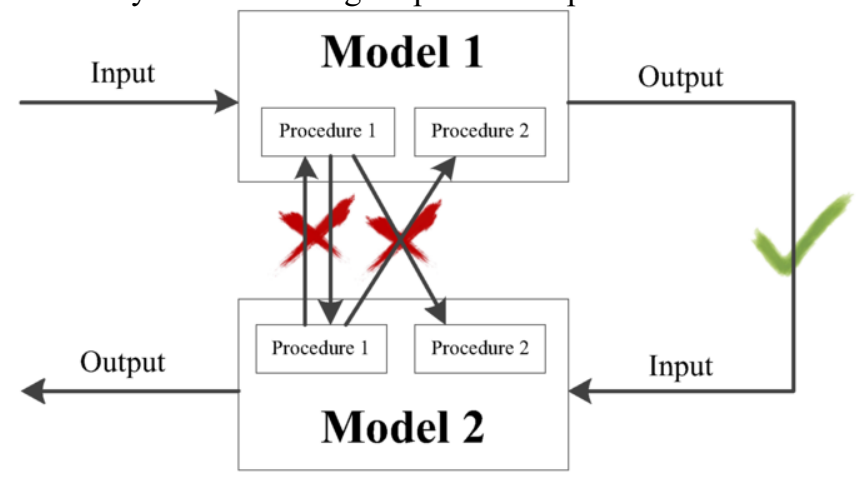

Figure 2. Interaction among different models.

\subsection{Data source}

Data layer performs unified storage and management of the data in the system. Data from various sources is preprocessed and converted into a standard format, and then stored in the data warehouse. The data stored in the system contains 5 types: real-time observation data, basic information data, business data, spatial data and multimedia data.

- Real-time observation data includes real-time data of monitoring objects such as hydrological stations, reservoirs, rainfall stations, and water users. Types of these data include flow data, water level data, rainfall data, temperature data, water intake data, etc. 
- Basic information data contains basic information of model objects, such as the names, addresses, and characteristic values of the reservoirs, hydrological stations, rainfall stations, water users, models, etc.

- Business data is the data generated when the system is running, such as configuration information, user information, operation logs, scheme information, scheme input, model results, etc.

- Spatial data mainly includes basic geographic information data, graphics and remote sensing image data, etc.

- Multimedia data is mainly audio and video data.

\subsection{Models Related to Water Dispatch}

The goal of water dispatch is to achieve a balance between water demand and water supply. Future water availability can be estimated through streamflow forecast model [16]. The water demand can be determined by user declaration. Then the water allocation model allocates water consumption according to the weights of different types, including domestic water, industrial water, agricultural water and ecological water. Finally, the operation plan of the reservoirs can be obtained by the water dispatch model. The goal of water dispatch model is to minimize the water supply shortage as much as possible by adjusting the outflow of each reservoir in each time period [17]. The adjustment is mainly in the dry season, while water levels of the reservoirs need to be kept at the flood limit water level during the flood season. Flowchart of water dispatch is shown in Figure 3.

As shown in Figure 3, the parameters of the streamflow forecast model are calibrate based on the historical rain, temperature and flow data. After inputting the observation rainfall and flow data of each station read from the database, the forecast model can predict the streamflow in the future. The water distribution plan is obtained from water demand data and streamflow forecasts data. Then the water dispatch model tries to generate operation plan which meet the water allocation plan as much as possible.

\subsection{Model Adapter}

When the user uses the water dispatch model, the Service Center sends a model calculation request to the Model Adapter. The model calculation input set by the user will be sent to the Model Adapter as the input view object (VO) along with the request. Then Model Adapter reads the data object (DO) through the Data Manager, including basic information data objects (Basic Data Object) and observation data objects (Observe Data Object). After that, the Model Adapter converts the VO sent by the Service Center and the DO read from the Data Manager into the business objects (BO) required by the models in the Model Platform. Basic Data Object is assembled into Reservoir Object, Section Object, Catchment Object, Water User Object, River Object, etc. according to the different types of model objects. Other object, for example, a Topology Object representing the topological relationship among objects is also assembled. Observe Data Object is transformed into rain series, water level series, flow series, water demand series, etc. These series will be attached to the corresponding model object. After the Model Platform receives the $\mathrm{BO}$, it executes the model calculation. Finally, the model results will be transformed into the VO required by the Service Center through the Model Adapter. Relationships among the system modules are shown in Figure 4. 


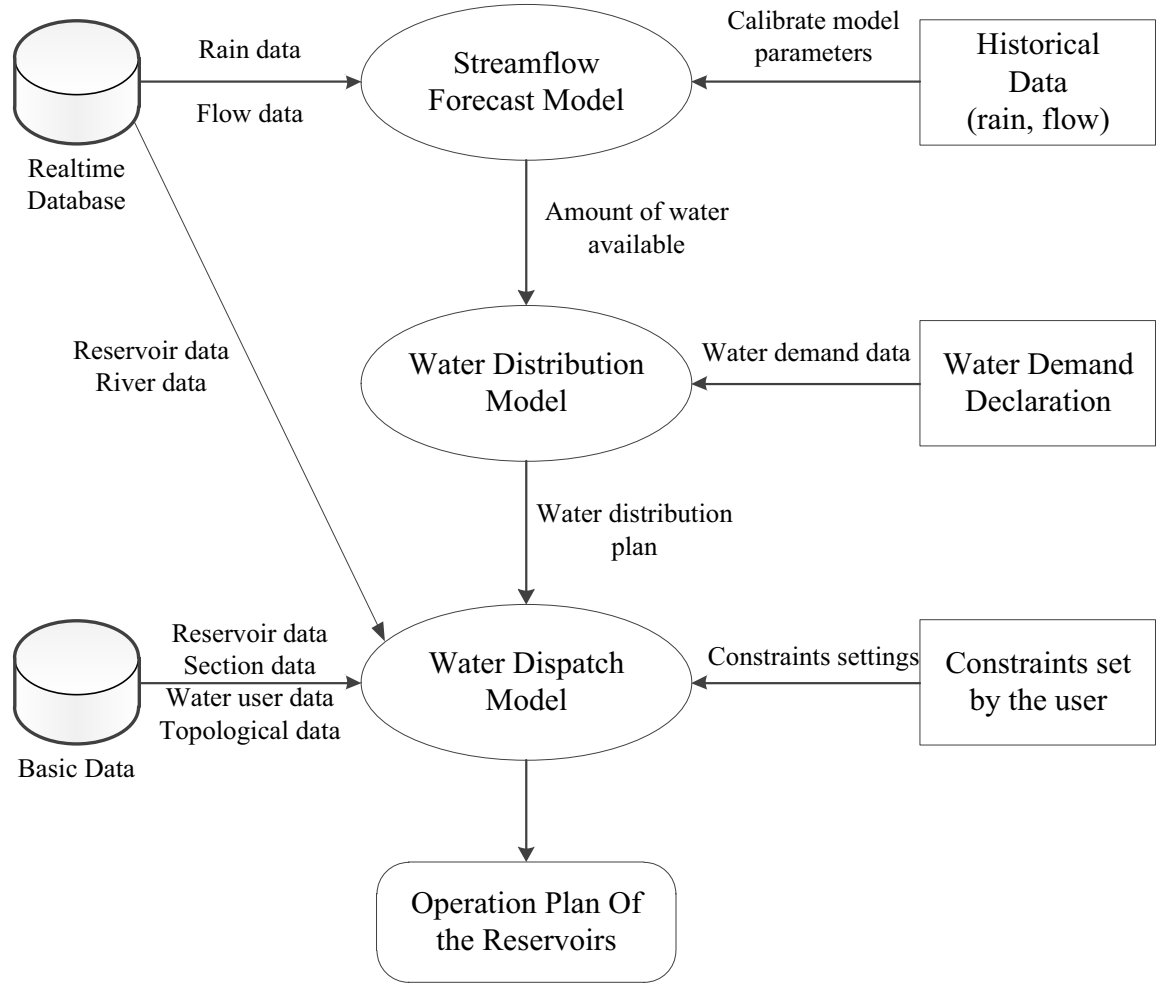

Figure 3. Dataflow of water dispatch.

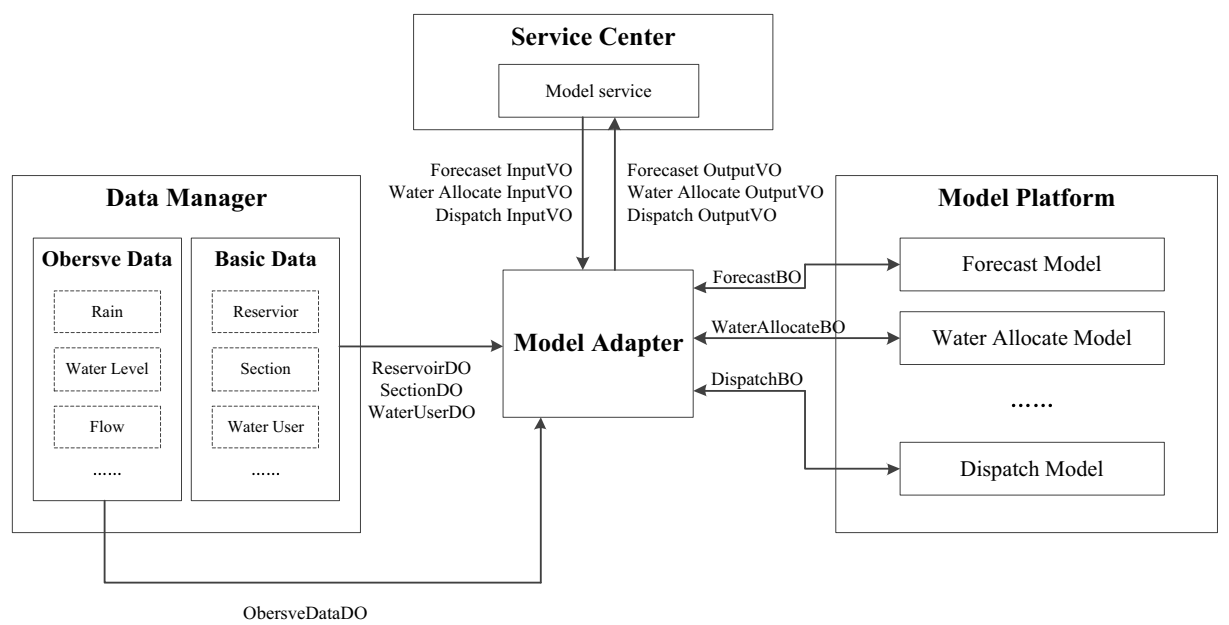

Figure 4. Relationship among the system modules. 


\section{Results and Discussion}

In this section we present an DSS for the water resource dispatching of Fu River. The Fu River is located in the eastern part of Jiangxi Province, China. It is the second largest river in Jiangxi Province. The water resource dispatching involves the water supply of 11 counties. There are two large reservoirs in the basin, with several hydrological stations shown in Figure 5.

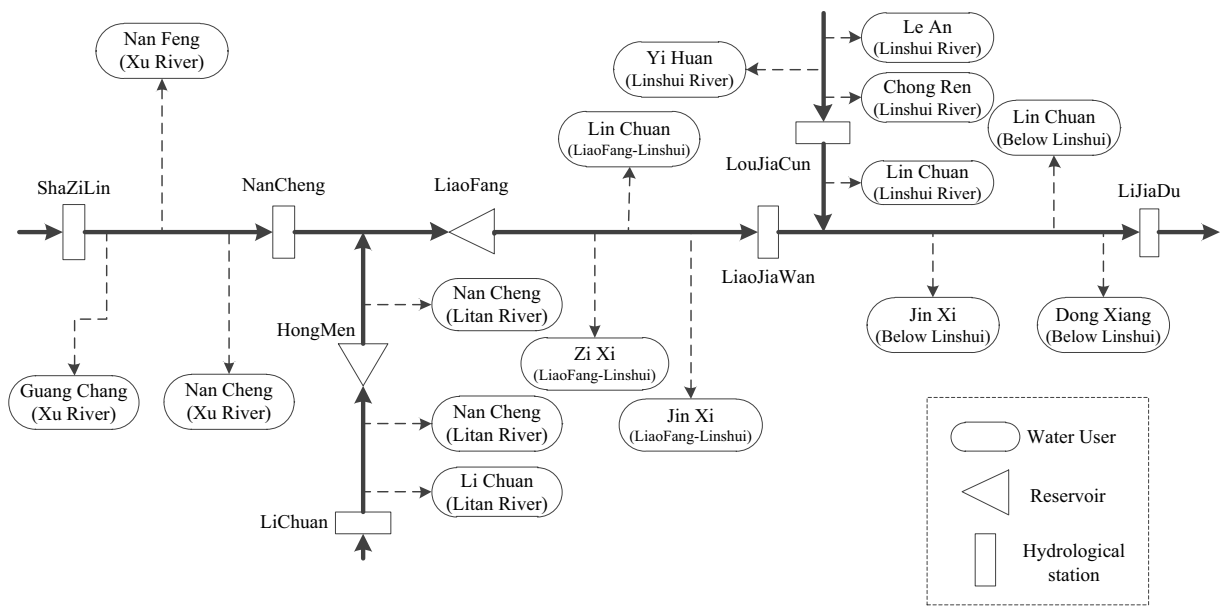

Figure 5. Topology of the Fu River basin.

In the DSS, every calculation of the model will generate a scheme, which saves the inputs and outputs of the model. The complete water dispatching process starts with streamflow forecasting. Then choose one of the three available water calculation methods provided by the system including the positive algorithm, the reciprocal algorithm and the empirical formula method to calculate the available water. After the water demand is declared and the water allocated is done, the water dispatch model is used to optimize the reservoir operation. If multiple schemes have been made, comparison among these schemes can be done through the system. Flowchart of the water dispatch is shown in Figure 6.

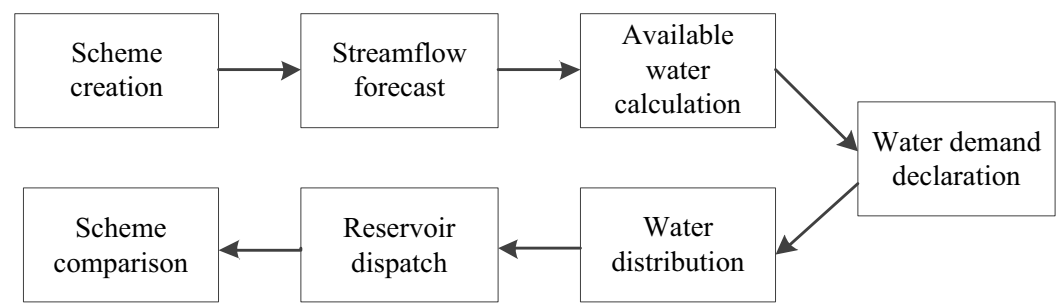

Figure 6. Flowchart of the water dispatch.

\subsection{Streamflow Forecast Module}

In streamflow forecast module, user can set the type of forecast model for each catchment area and the parameters of the corresponding model. After clicking the forecast button, the system automatically collects observation data from the data layer and then do the 
prediction. The forecast results are displayed in the form of graphs and tables, such as forecast streamflow, streamflow of the previous year and average annual streamflow. Figure 7 shows one of the user interfaces of the streamflow forecast module. In Figure 7, we can see the monthly streamflow of each section predicted by the forecast model, while some statistical information is also provided.

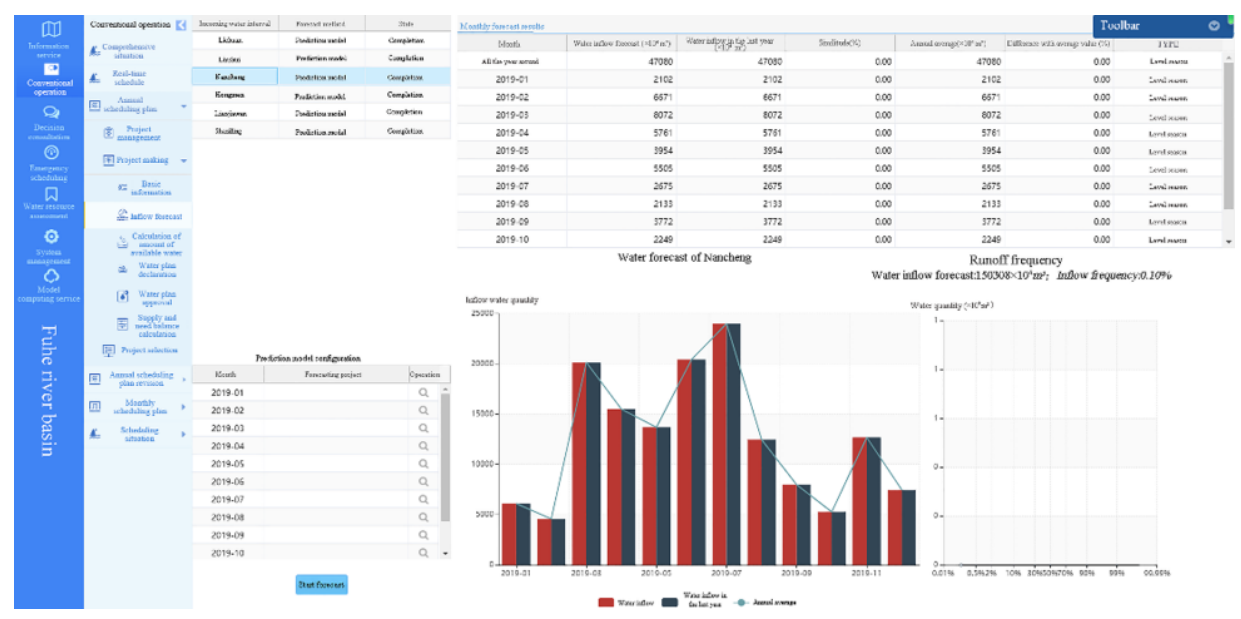

Figure 7. User interface of the streamflow forecast module.
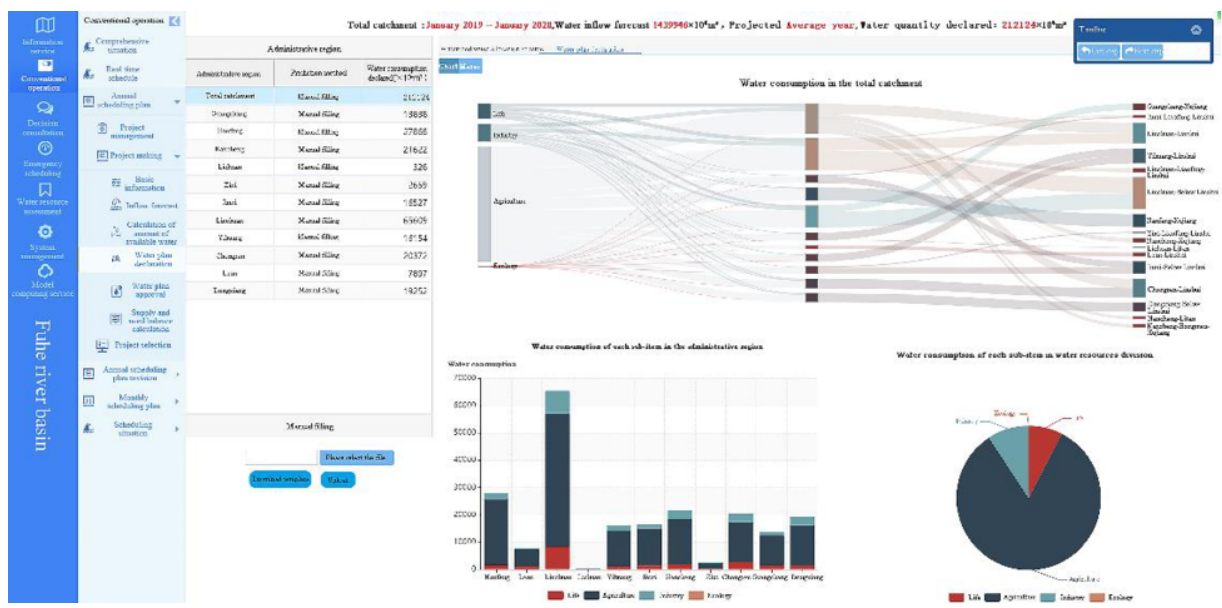

Figure 8. User interface of the water demand declaration module.

\subsection{Water Demand Declaration Module}

In water demand declaration module, user needs to enter the water demand of each water user unit in each time period. User downloads the excel template for water demand declaration, then fill in the corresponding information in the template, and finally upload 
it to the system. The system will make statistics for each water user unit and water type. As shown in Figure 8, the system displays the statistical information of domestic, industrial, agricultural and ecological water requirements for each county. Statistical information for the entire basin is also given.

\subsection{Water distribution module}

In water distribution module, system will allocate the available water according to the priority of water user and water type if the available water cannot meet the water demand. Figure 9 shows one of the user interfaces of the water distribution module. The system lists the distribution results of domestic water and ecological water for each water use unit in each month. In general, domestic water demand and ecological water demand have higher priority than that of industrial water demand and agricultural water demand.

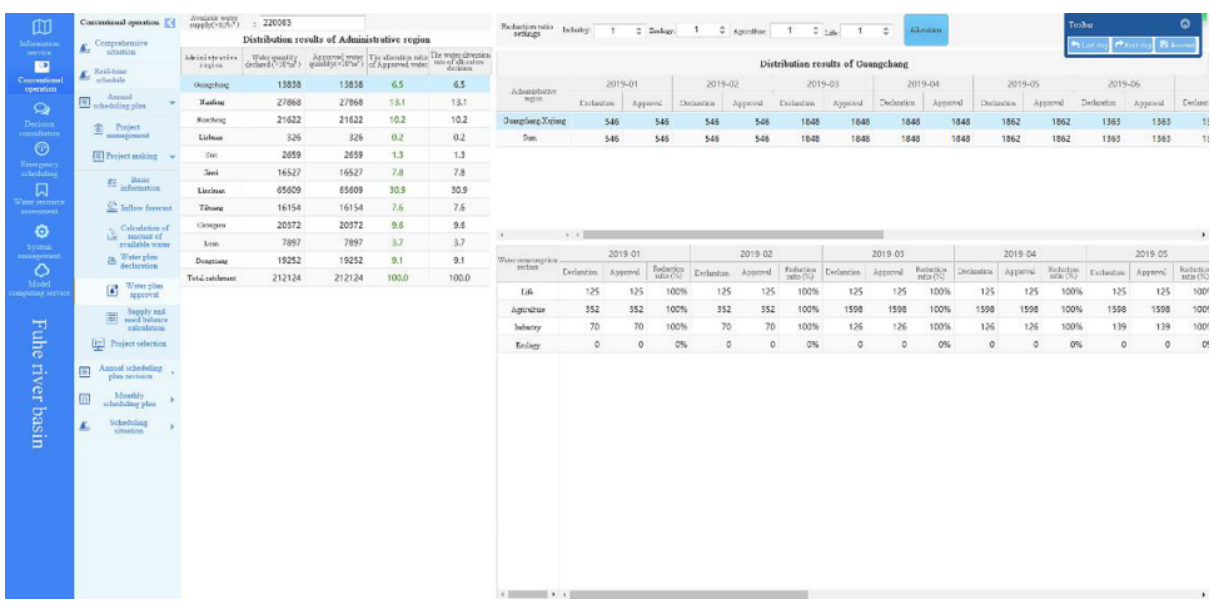

Figure 9. User interface of the water distribution module.

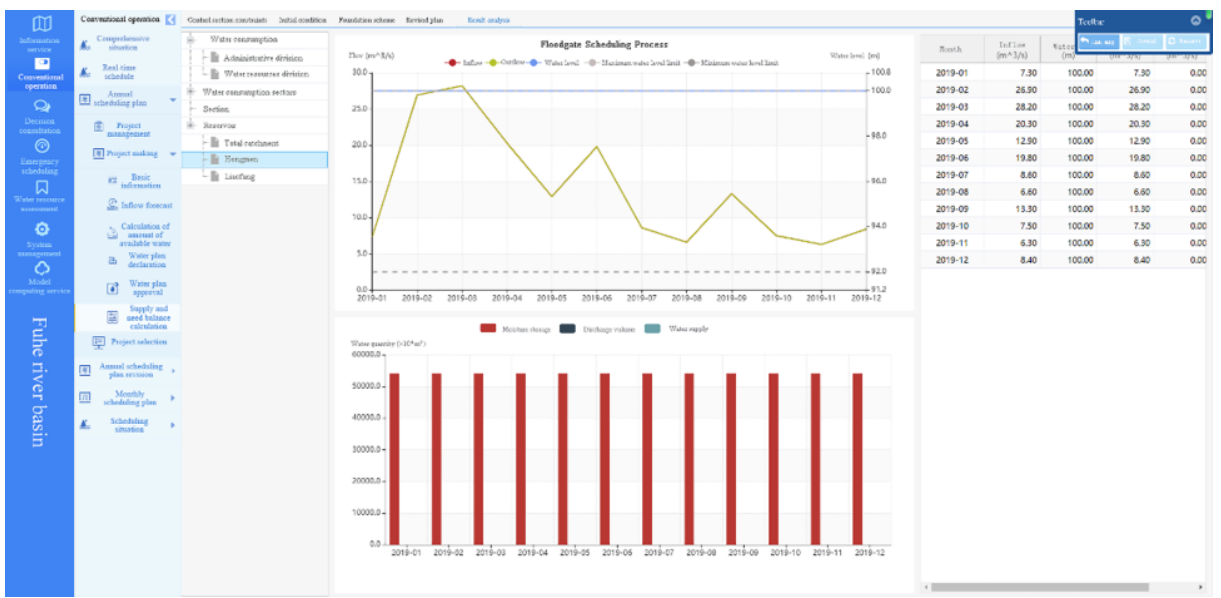

Figure 10. User interface of the water dispatch module. 


\subsection{Water dispatch module}

In water dispatch module, user can set the control section constraints and reservoir constraints such as maximum water level, minimum flow, etc. After clicking the calculate button, system will run the water dispatch model to generate a reservoir scheduling scheme. Including the discharge process of the reservoir at each time period, as well as the water supply of each water unit. Figure 10 shows one of the user interfaces of the water dispatch module. In figure 10, the operation process of Hongmeng Reservoir is given, such as water level process, outflow process, etc.

\section{Conclusion}

This paper discussed the design of a water resources dispatch decision support system. The DSS is designed as five parts, including Application, Service Center, Data Manager, Model Adapter and Model Platform. Model Adapter and Model Platform are the featured designs of this article. Model platform integrates mathematical models and provides computing services. The interaction between the model and the system is realized through the Model Adapter. The Application provides users with a friendly User Interface, and offers a unified entrance for all users to access the system. The Service Center contains all the business services of the system, such as logical business services, log services, monitoring services, etc. Data Manager performs unified storage and management of the data in the system. Data from various sources is preprocessed and converted into a standard format, and then stored in the data layer. The system realizes the complete process design from data to water dispatch model calculation.

In case study, we implemented the Fu River Basin Water Dispatching System according to these designs. Using the hydrological and meteorological observation data collected by the system, it is possible to predict the future streamflow of the river. After declaring the water demand of each county and city, the system can apply the water allocation model to allocate water resources to each water user reasonably. Then the operation plan of the reservoir can be obtained by the water dispatch model. User can get the recommended operation plan of the reservoir and the corresponding water supply result. The proposed system can provide technical support and assistance for the decision makers, which also provide an effective demonstration for water resources management in other rivers.

\section{References}

[1] Fg A, Ac A , Eg B , et al. Dynamic, multi-objective optimal design and operation of water-energy systems for small, off-grid islands - ScienceDirect. Applied Energy. 2019; 250:605-616.

[2] Jin W , Chang J , Wang Y, et al. Long-term water-sediment multi-objectives regulation of cascade reservoirs: A case study in the Upper Yellow River, China. Journal of Hydrology. 2019; 577:123978.

[3] Abdulbaki D, Al-Hindi M, Yassine A, et al. An optimization model for the allocation of water resources. Journal of Cleaner Production. 2017; 164(oct.15):994-1006.

[4] Ahmad I, Fan Z, Liu J , et al. A linear bi-level multi-objective program for optimal allocation of water resources. Plos One. 2018; 13(2):1-25.

[5] Nematian J, Movahhed S R. An extended multi-objective mixed integer programming for water resources management through possibility theory. Ecological Informatics. 2019; 54:100992.

[6] Blair, P., Buytaert, W. Socio-hydrological modelling: a review asking "why, what and how?". Hydrology and Earth System Sciences. 2016; 20(1):443-478. 
[7] Li T,Dong Y, Liu Z. A review of social-ecological system resilience: Mechanism, assessment and management. Science of The Total Environment. 2020; 723. 138113.

[8] $\mathrm{Pb} \mathrm{A}, \mathrm{Gg} \mathrm{A}, \mathrm{Ss} \mathrm{B}$. An actionable hydroeconomic Decision Support System for the assessment of water reallocations in irrigated agriculture. A study of minimum environmental flows in the Douro River Basin, Spain[J]. Journal of Environmental Management. 2021; 298:113432.

[9] Ateș K, Şahin C, Kuvvetli Y, et al. Sustainable production in cement via artificial intelligence based decision support system: Case study. Case Studies in Construction Materials. 2021; 15: e00628.

[10] Quiones-Grueiro M, Prieto-Moreno A, Verde C, et al. Decision Support System for Cyber Attack Diagnosis in Smart Water Networks. IFAC-PapersOnLine. 2019; 51(34):329-334.

[11] Ahmadi A, R Kerachian, Skardi M, et al. A Stakeholder-based Decision Support System to Manage Water Resources. Journal of Hydrology. 2020; 589(1):125138.

[12] Anzaldi G , Rubion E , Corchero A, et al. Towards an Enhanced Knowledge-based Decision Support System (DSS) for Integrated Water Resource Management (IWRM). Procedia Engineering. 2014; 89:1097-1104.

[13] Pierleoni A, Camici S , Brocca L, et al. Climate Change and Decision Support Systems for Water Resource Management. Procedia Engineering. 2014; 70:1324-1333.

[14] Li Y . Towards fast prototyping of cloud-based environmental decision support systems for environmental scientists using R Shiny and Docker. Environmental Modelling \& Software. 2020; 132: 104797.

[15] Lazoglou M , Angelides D . Development of a spatial decision support system for land-use suitability assessment: The case of complex tourism accommodation in Greece. Research in Globalization. 2020; 2:100022.

[16] Liu Y, Sang Y, Li X, et al. Long-Term Streamflow Forecasting Based on Relevance Vector Machine Model. Water. 2016; 9(1):9.

[17] Sun J, Lei X, Liang J, et al. A uniform spatial allocation strategy in solving water resources optimization dispatch problem. MATEC Web of Conferences. 2018; 246. 